NASA Technical Memorandum 102000

\title{
Investigation of Weibull Statistics in Fracture Analysis of Cast Aluminum
}



Frederic A. Holland, Jr., and Erwin V. Zaretsky

Lewis Research Center

Cleveland, Ohio

Prepared for the

Failure Prevention and Reliability Conference

sponsored by the American Society of Mechanical Engineers

Montreal, Canada, September 17-20, 1989 


\section{ERRATA}

NASA Technical Memorandum 102000

INVESTIGATION OF WEIBULL STATISTICS IN FRACTURE ANALYSIS OF CAST ALUMINUM Frederic A. Holland, Jr., and Erwin V. Zaretsky

Page 5, SUMMARY OF RESULTS, numbered paragraph 4 should read

4. The ASME pressure vessel code for the design of spherical pressure vessel shells was found to be much more conservative than the probabilistic design methodology presented. 


\title{
ORIGINAL PAGE IS OF POOR QUALTTY.
}

\author{
INVESTIGATION OF WEIBULL STATISTICS IN FRACTURE ANALYSIS OF CAST ALUMINUM \\ Frederic $A$. Holland, Jr., and Erwin V. Zaretsky* \\ National Aeronautics and Space Administration \\ Lewis Research Center \\ Cleveland, Ohio 44135
}

\section{ABSTRACT}

The fracture strengths of two large batches of A357-T6 cast aluminum coupon specimens were compared by using two-parameter Weibull analysis. The minimum number of these specimens necessary to find the fracture strength of the material was determined. The applicability of three-parameter Weibull analysis was also investigated. A design methodology based on the combination of elementary stress analysis and Weibull statistical analysis is advanced and applied to the design of a spherical pressure vessel shell. The results from this design methodology are compared with results from the applicable ASME pressure vessel code.

\section{INTROOUCTION}

The ability to design static structures and rotating machine components that can survive anticipated loads and stresses in both normal and overload applications is an important safety and economic requirement. Common design practice for many industrial applications tends toward placing large safety factors in the design of structures and machinery. Although this practice results in satisfactory operation, usually the machine element is larger, weighs more, and utilizes materials less efficientiy. An alternative is to design structural elements to operate at loads closer to their failure strength and then proof test the end product to ensure the safety of those items that will reach the consumer. However, this method can also be costly, perhaps more so than designing with a conservative safety factor.

In aerospace applications, designing in a conservative mode with large safety factors is precluded because the resultant structure would be either too heavy or too bulky to fly. Hence, designing closer to the failure limit is almost mandatory in aerospace applications. The issue becomes one of how to determine the failure limit of a structure or machine element.
A further issue confronting the engineer is the determination of the stress in a structure below which no fatigue, creep, or fracture failures will occur. For pressure vessels elaborate sets of standards have been developed that ensure with reasonable engineering certainty that for known materials no failure will occur over the usable design life (ASME, 1987). However, for new or untested materials for which no field experience exists, how should this determination be made? What kind of tests should be conducted? How many specimens should be run? How can results from coupon specimens be extrapolated to full-size structures? How can the probability of survival of a structure subjected to known loads be determined with reasonable engineering certainty?

Many investigators over the years have approached these questions in the areas of fracture and fatigue (Weibull, (1939), Helier (1972), Little and Ekvall (1979), Abelkis and Hudson (1980), Augusti, et al. (1984), Ioannides and Harris (1985), and Zaretsky (1987)). Primary consideration has been given to the determination of low failure probabilities. That is, the probability that a structure will fail will be less than 1 percent. This means that there is greater than 99 percent probability that the structure will survive. However, because of the volume effect recognized by W. Weibull (1939), the probability of survival for a large structure will be less than that for a smaller structure with the same operating stress.

In view of the aforementioned, it was the objective of the work reported herein (i) to analyze large sample sizes by using two-parameter Weibull analysis to determine the comparative fracture strength of two batches of the same material, (2) to determine by using Weibull statistics the minimal specimen size necessary to determine the fracture strength of a material, (3) to determine by combining design and statistical methods the relative weight and survivability of a pressure vessel, and (4) to investigate the applicability of three-parameter weibull analysis to fracture analysis.

${ }^{\star}$ Fellow, ASME. 


\section{STATISTICAL METHOD}

The Weibull distribution function linearizes most engineering data distributions, making it possible to estimate a population of infinite size from small amounts of data (Weibull; 1939, 1951). The Weibull distribution function can be expressed as

$$
F(x)=1-\exp \left[-\left(\frac{x-x_{u}}{x_{0}}\right)^{m}\right]
$$

where for this investigation the parameters are $F(x)$ statistical fraction of specimens that failed at given stress or lower

$x \quad$ stress

$x_{u}$ stress below which no specimens failed (location parameter)

$x_{0} \quad$ characteristic strength, stress at which 63.2 percent of specimens falled

m Weibull slope or modulus

The three weibull parameters $x_{u}, x_{0}$, and $m$ are assumed to be constants of the material. When $x_{u}$ is assumed to be zero, the three-parameter Weibull distribution function becomes known as a two-parameter Weibull distribution function. The Weibull slope or modulus $m$ is a measure of material homogeneity. A high value of $m$ indicates a high degree of homogeneity.

Equation (1) can be rearranged to form an equation for a straight line as follows:

$$
\ln \ln \left[\frac{1}{1-f(x)}\right]=m\left[\ln \left(x-x_{u}\right)-\ln x_{0}\right]
$$

In this form a plot of the distribution function should be linear in a coordinate system where the ordinate is $\ln \ln \{1 /[1-F(x)]\}$ and the abscissa is $\ln \left(x-x_{u}\right)$. After the method of Johnson (1959) is used to obtain values of $F(x)$, the data set is arranged in order of increasing stress. Each stress value then has an order number according to its position in the list. Then from applicable statistical tables of median ranks, each number is converted to a median rank, which is the value of $F(x)$ for that particular data.

Values of $F(x)$ and $x-x_{u}$ can be plotted on Weibull probability paper as $\ln \ln \{1 /[1-F(x)]\}$ or in $\ln \{1 /[S(x)]\}$, where $S$ is the probability of survival (equal to $1-f(x)$ ) as a function of the $\log$ of strength. The plot will be linear for the correct value of $x_{u}$, which is also called the location parameter.

If the original plot of the data is a straight line, then $x_{y}$ is assumed to be zero (i.e., the minimum stress below which no specimens can fail is zero). If the original plot concaves downward, then there is some finite stress below which no specimens fail. The true value of $x_{u}$ can be found by substituting assumed values into the expression $x-x_{u}$ until the Weibull plot becomes 1 inear.

\section{RESULTS AND DISCUSSION}

Two separate batches of A357-T6 cast aluminum were fracture tested by the U.S. Air Force in accordance with ASTM standards (ASTM, 1986). These data are shown in the two-parameter Weibull plots of Fig. 1 . There were 354 coupon specimens fracture tested of batch 1 and 388 of batch 2 . These data were subjected to both two-parameter and three-parameter Weibull analyses. The results of these analyses were applied to the design of a hypothetical pressure vessel shell to determine the order of merit for weight and survivability.

\section{Comparative Fracture Strength}

A material's fracture strength is usually defined as the mean or average stress at which specimen failure occurs. The mean fracture strengths for batches 1 and 2 (given in Table I) were 357.0 and $361.0 \mathrm{MPa}$ (51 783 and 52362 psi), respectively. The difference between these values is insignificant, oniy

1.1 percent.

Since high reliability is usually desired, more concern is generally given to the prediction of fracture strengths at low probabilities of failure rather than at the mean. Figure 2 shows the estimated failure distributions of batches 1 and 2 extrapolated to show probabilities of failure to the 0.0001 -percent level. The $x$ axis was scaled linearly to better show the differences in the prediction of fracture strength between the two batches than could be realized from a Weibull plot. The differences in the estimate of fracture strength increased between batch 1 and batch 2 with decreasing probability of failure. At a probability of failure of 0.0001 percent ( 99.9999 percent probability of survival), the estimated fracture strengths were $270.1 \mathrm{MPa}$ (39 $178 \mathrm{psi}$ ) for batch 1 and $234.1 \mathrm{MPa}$ (33 $948 \mathrm{psi}$ ) for batch 2. This difference is 14.3 percent.

\section{Comparison of Weibull Parameters}

The two-parameter Weibull plots of batches 1 and 2 shown in Fig. I exhibit very high Weibull slopes, thereby indicating a high degree of material homogeneity. Table I shows the results of this analysis. The Weibull slopes or moduli for batches 1 and 2 are 47.5 and 30.6 , respectively. The fact that these slopes differ by 43.3 percent is at first deceiving. It is important to realize that the weibull modulus, or Weibull slope, is defined as the tangent of the angle (in degrees) of the curve. As an angle approaches $90^{\circ}$, the tangent of the angle rapidly approaches infinity. since the weibull plots for batches 1 and 2 are nearly vertical (almost $90^{\circ}$ ), a slight difference between the respective angles results in a large difference in the tangents, and hence the Weibull slopes. For example, a Weibull modulus of 47.5 represents an angle of $88.8^{\circ}$, and a modulus of 30.6 represents an angle of $88.1^{\circ}$. The difference in angle is less than $1^{\circ}$. Hence, there is actually no significant difference between the slopes of batches? and 2 .

The characteristic strengths of the two batches were found to vary by only 1.73 percent, being $361.2 \mathrm{MPa}$ ( $52396 \mathrm{psi}$ ) for batch 1 and $357.6 \mathrm{MPa}$ (53 311 psi) for batch 2 . These differences are also insignificant. For the two batches of cast aluminum considered here, the Weibull parameters were found to be nearly the same, as commonly assumed.

\section{Determination of Minimal Sample Size}

Large sample sizes are generally desirable in statistical analysis because of the consistency and accuracy in the results obtained. The disadvantage of such a practice is, obviously, the increase in cost. An important issue confronting the engineer then is the minimal sample size needed to determine a material's fracture strength.

The stresses at which specimen failure occurred within the batch were ranked in increasing order. Random numbers were then generated by a computer programmed to generate numbers only within the range of the number 
of specimens contained in the batch. For example, since there were 354 specimens in batch 1, random numbers were generated with in the range 1 to 354 . The stresses ranked in the batch corresponding to the numbers generated randomily were selected to form data subsets consisting of 10,20 , and 30 samples. Hence, these samples represented collections of data that could have been obtained from fracture experiments had only so many coupon specimens been used.

We ibull plots of the computer-generated samples for batch 2 are shown in Fig. 3. For easy comparison, these samples, along with their parent distributions, are shown plotted on a semilogarithmic graph in Fig. 4 A summary of the results is given in Table II. As can be seen for batch 1 , using only 30 samples yielded nearly the same estimated fallure distribution as that of the parent (354 samples). There was also no significant difference in using 10 samples. The overall failure distribution derived from 20 samples deviated the most from the parent distribution.

For batch 2 all the computer-generated samples gave different failure distributions than the parent distribution ( 388 samples). The failure distribution derived from 20 samples was the closest to that of the parent, being only slightly better than 30 samples. Ten samples deviated the most from the parent distribution. However, the characteristic strength and the mean strength obtained from using 10 samples were not significantly different from those of the parent values.

The effect of varying the sample size on the Weibull parameters and the fracture strengths both at the mean and the estimation at the 0.0001 -percent failure probability level is also shown in Table II. The variation of fracture strength from the parent distribution was less than 15.5 percent for sample sizes of 20 or more, or approximately the same as the variation from batch 1 to batch 2. This would suggest that for an estimate of high probabilities of survival, a minimum sample size of 20 be used.

Generally, the Weibuil slope or modulus obtained from using only 10 samples was the least accurate among all the computer-generated samples in comparison with the slope of the parent distribution. However, a variation in modulus from 30.6 to 94.5 means a change in angle of only $1.2^{\circ}$

DeSalvo (1970) studied the effect of sample size on estimating the Weibull slope on from computergenerated samples of parent distributions. For the range of $m$ values ( 3 to 30 ) and sample sizes ( 10 to 100$)$ studied, the coefficient of variation for the estimate of $m$ was found to be about $(1 / n) 0.5$

According to this result, a variation in $m$ of 31.6 percent could then be expected from a sample size of 10 .

Effect of Sample Size on Confidence Limits

The fewer the samples used in estimating the failure distribution, the less confidence can be had in the failure predictions from these distributions. Johnson (1959) discusses the mathematics of determining the confidence limits of the failure distribution. Using his method the effect of varying sample size on confidence limits was studied.

Six separate groups of samples, having sample sizes of $88,35,17,11,8$, and 7 , were formed from batch 1 . The subgroup consisting of 88 samples was formed by extracting every fourth data point from the ordered data of batch 1 . Similarly, the $35,17,11$, 8 , and 7 sample sizes were formed by taking every loth, 20th, 30th, 40th, and 50th data point, respectively. Forming data subsets in this manner was necessary in order to keep the estimated failure distributions approximately the same for each sample group, since confidence limits are also affected by the Weibull slope.

Computer-generated plots showing the Weibull lines obtained from the subgroups in addition to the ir respective 95-percent confidence bands are shown in Fig. 5. The 95-percent confidence bands indicate that in 95 percent of all possible cases the true population will fall within the enclosing bands. As can be seen. the fewer the number of samples used, the wider is the confidence band surrounding the distribution. This indicates that less confidence can be had in population estimates obtained from smaller sample sizes, the degree of which can be seen in Fig. 5.

\section{Determination of Minimum Failure Stress}

A two-parameter weibull distribution was used in Fig. I to characterize the strength probability for cast aluminum. That is, the location parameter $x_{u}$ is zero. This implies that the minimum stress below which no specimens fail is zero. This idea is a theoretical convenience. However, experience suggests that there may be nonzero values of stress below which specimens will always survive fast fracture. The assumption of a zero minimum strength is perhaps too conservative for many applications where cost, weight, or both are critical. This idea was also recognized by Shih (1980), who suggested that a three-parameter Weibull distribution be used to model the failure distribution of brittle materials.

The two-parameter Weibull plots of cast aluminum fracture data shown in Fig. I conform very well to a straight line. For such a situation can a nonzero value of $x_{u}$ be obtained? A methodology to meet this objective was explored.

The fracture strength of the weakest specimen in the batch was used as the initial estimate of $x_{u}$. The quantity $x-x_{u}$ was then obtained for each point by subtracting this estimate of $x_{u}$ from the fracture strength of each specimen. These new values were plotted on Weibull paper with the same failure probabilities as before. This is an established method for finding $x_{U}$ as given by Moyer et al. (1962).

Smaller estimates of the location parameter $x_{u}$ were found to result in greater linearity. In fact, the Weibull plot became more linear as $x_{u}$ approached zero. However, there appeared to be a point in the process where increasingly smaller values of $x_{u}$ resulted in very little change in the linearity of the data. The value of $x_{u}$ at this point was then taken to be the most accurate estimate. Following this method a location parameter of $268.9 \mathrm{MPa}$ (39 $000 \mathrm{psi}$ ) was assumed for batch 1 and $262.0 \mathrm{MPa}(38000 \mathrm{psi}$ ) for batch 2 .

Figure 6 shows the fallure distribution of batch 2 resulting from three-parameter weibull analysis. The results of using two- and three-parameter weibull statistics are compared in Fig. 7. For both batches the estimated probabilities of failure between the twoand three-parameter models became increasingly different as the fracture probability decreased. Assuming that there is indeed a nonzero minimum strength below which no specimens will fail, these results indicate that there are exceptions to the established rule for determining the location parameter, since any nonzero value substituted for $x_{u}$ did not result in greater linearity of the data. Otherwise, it must be assumed that there is a probability of fallure at any stress.

Extrapolation of Test Specimen Data to Full-Size Structures

Three methods are typically used for establishing the relationship between a structure's strength and its 
reliability. These methods include testing full-scale models, small-scale models, or small specimens.

Testing full-scale models is the simplest approach because it provides a direct relationship between reliability and strength for the full-size structure.

This method, however, is neither practical nor cost effective.

For tests on small-scale models and small specimens a theory is needed to determine the effect of size on the fracture strength of the structure. The weakest link theory (WLT) fills this need. This theory is based on the idea that physical bodies, envisioned as divided into small volumes, can be modeled as a chain, with the strength of the chain determined by its weakest link. This is a conservative theory, since it assumes that failure at any point is failure of the entire structure. In other words, it is assumed that nothing prevents a crack from propagating throughout the material. The probability of survival $S$ of a chain consisting of $n$ identical links is then

$$
S=S_{j}^{n}
$$

where $S_{j}$ is the probability of survival of each link. For two structures of identical material with similar geometries (and stress conditions), the probability of survival of the smaller structure of stressed volume $V_{1}$ can be scaled to that of the larger structure of stressed volume $V_{2}$ by

$$
s_{2}=s_{1}^{\left(V_{2} / V_{1}\right)}
$$

This relationship can be used to scale coupon specimens to full-size structures by a method proposed by

Zaretsky (1987). For brittle components possessing nonuniform stress distributions and multiaxial stress states, a methodology for determining the structure's reliability was proposed by Barnett et al. (1966).

For situations where the stress distribution can be assumed to be uniform, the following design methodology is proposed:

(1) Perform a Weibull analysis on tensile test specimens with gage volume $V_{1}$, obtaining Weibull parameters $m, x_{0}$, and $x_{U}$.

(2) Perform a stress analysis of the structure. Relate the operating stress $x$ to a structural parameter such as the wall thickness of a pressure vesse?.

(3) Assume a value for the parameter or parameters to be determined and calculate the resulting operating stress.

(4) Calculate the stressed volume $V_{2}$ of the proposed structure.

(5) Determine the structure's reliability $S_{2}$ by direct scaling:

$$
s_{2}=\left\{\exp -\left[\left(\frac{x-x_{u}}{x_{0}}\right)^{m}\right]\right\}^{v_{2} / v_{1}}
$$

Note that for brittle materials such as ceramics under multiaxial stress, it is necessary to use a multiaxial stress theory to determine the effect of this stress state on the fracture probability. Combine this theory with Eq. (5) and calculate the probability of survival.

(6) Repeat steps 3 to 5 until a satisfactory reliability is obtained.

As a demonstration, this methodology was applied to the design of a hypothetical spherical pressure vessel shell, using the A357-T6 cast aluminum data analyzed in this report. The density of this material is
$2.68 \mathrm{~g} / \mathrm{cm}^{3}\left(0.097 \mathrm{lb} / \mathrm{in}^{3}\right)$. The inside radius $R$ of the shell and the internal pressure $P$ were given as $0.305 \mathrm{~m}$ (12 in.) and $1.72 \mathrm{MPa}(250 \mathrm{psi})$, respectively. The shell thickness $t$ was determined from a required reliability of 99.999998 percent.

The equation relating the stress $x$ in the wall to the thickness was derived from elementary stress andysis (Gere and Timoshenko, 1984) and is given by

$$
x=\frac{P R}{2 t}
$$

Assuming a value for $t$, the stress in the wall was calculated from Eq. (6), and the stressed volume $V_{2}$ of the shell was determined from

$$
V_{2}=\frac{4}{3}\left[(R+t)^{3}-R^{3}\right]
$$

The probability of survival of the shell was then calculated by substituting the values of $x$ and $V_{2}$ into Eq. (5) along with the Weibull parameters obtained from Weibull analysis of the cast aluminum specimens with gage volume $V_{l}$. Sample calculations performed in Appendix A show each step in the design algorithm. Appendix $B$ gives the derivation of a single design equation for spherical pressure vessel shells.

Figure 8 shows the effect of shell thickness on the structure's probability of survival. Within a very small range the probability of survival was highly sensitive to changes in the shell thickness. For shell thicknesses between 0.80 and $0.93 \mathrm{~mm}<0.032$ and $0.036 \mathrm{in.}$ ), the probability of survival increased from 0.0008 to 98.66 percent for batch 1 . The probability of survival for a shell designed by using the data of batch 2 was similarly observed to go from 0.0005 to 98.5 percent for an increase in wall thickness of only $0.211 \mathrm{~mm}(0.0083 \mathrm{in}$.$) .$

The relationship between the weight of the spherical shell and the probability of survival is shown in Fig. 9. The probability of survival increased from nearly 0 to over 99 percent with the addition of less than $0.70 \mathrm{~kg}(1.5 \mathrm{lb})$ to the total weight of the structure.

\section{Comparison with ASME Pressure Vessel Code}

With probabilistic design methods structural parameters are often determined by the required reliability. Conventional design methods usually involve safety factors that are used to ensure that the operating stress will never exceed the strength of the material. The size of the structure is then determined by the safety factor used. Safety factors are typically used in design codes prescribed by the American Society of Mechanical Engineers (ASME).

A comparison was made between the results of designing the spherical shell described previously by using Weibull statistics and designing it by using the applicable ASME code (ASME, 1987). The required shell thickness according to this code is given by

$$
t=\frac{P R}{2 S E-0.2 P}
$$

where $S$ is the maximum allowable stress and is defined as the ultimate tensile strength divided by a safety factor of 4 . From military standard specifications the ultimate tensile strength of A357-T6 cast aluminum is $310.3 \mathrm{MPa}$ (45000 psi) (Department of Defense, 1987). For this comparison the value of the joint efficiency $E$ was taken as unity since joints are not accounted for in the Weibull design me thodology. 
Table III shows the thickness and weight of the pressure vessel shell resulting from the application of both design methods. The minimum shell thickness from the ASME code was $3.39 \mathrm{~mm}(0.133 \mathrm{in}$.) and the weight was $10.8 \mathrm{~kg}(23.8 \mathrm{lb})$. But for a reliability of 99.999998 percent, the shell designed from weibull statistics had a thickness of only $0.141 \mathrm{~mm}(0.055 \mathrm{in}$.) and a weight of $4.4 \mathrm{~kg}(9.8 \mathrm{lb})$. According to Weibull's theory the shell designed by the ASME code has virtually no chance of fracture failure (assuming there are no major flaws). However, the weight of the shell can be cut in half and still have an extremely high probability of survival. A correlation between probability of survival and safety factor for a spherical pressure vessel shell is shown in Fig. 10. At a safety factor of 1.25 the probability of survival was 100 percent.

\section{SUMMARY OF RESULTS}

Two separate batches of cast aluminum were fracture tested in accordance with ASTM standards by the U.S. Air Force. There were 354 coupon specimens fracture tested in batch 1 and 388 in batch 2 . These data were subjected to both two-parameter and threeparameter Weibull analyses. The results were applied to the design of a hypothetical pressure vessel shell to determine the order of merit for weight and survivability. The following results were obtained:

1. The mean fracture strengths for batches 1 and 2 of A357-T6 cast aluminum were 357.0 and $361.0 \mathrm{MPa}$ (51 783 and 52362 psi), respectively. The difference between these values is insignificant, only 1.1 percent. However, at a 99.9999 percent probability of survival $(0.0001$ percent probability of failure), the estimated fracture strength varied by 14.3 percent.

2. The mean fracture strengths determined by using $10,20,30$, and up to 388 test specimens were not significantly different. At a 99.9999 percent probability of survival the variation of fracture strength was less than 15.5 percent for sample sizes of 20 or more, or approximately the same as the variation from batch to batch. This suggests a minimum sample size of 20 to determine an estimate of the probability of survival for materials such as cast aluminum.

3. According to the established rule for determining the location parameter on the basis of the linearity of the original two-parameter Weibull plot of the data, the stress below which no specimens fail must be assumed to be zero for A357-T6 cast aluminum.

4. The ASME pressure vessel code for the design of probabilistic spherical pressure vessel shells was found to be much more conservative than the design methodology presented.

\section{ACKNOWLEOGMENTS}

The authors wish to acknowledge and thank William F. Brown, Jr., Consultant and NASA Distinguished Research Associate for supplying the fracture data and for his technical recommendations and comments, which have been incorporated throughout this paper.

APPENDIX A - SAMPLE CALCULATIONS

Theoretical Stress in Thin-Walled Spherical Pressure Vessel

$$
x=\frac{P R}{2 t}
$$

where

$x$ stress

$P \quad$ internal pressure

$R$ inside radius

$t$ wall thickness

Using $P=1.72 \mathrm{MPa}(250 \mathrm{psi}), R=0.305 \mathrm{~m}$ (12 in.), and $t=1.02 \mathrm{~mm}(0.040 \mathrm{in.})$ gives

$$
x=\frac{\left(1.72 \times 10^{6}\right)(0.305)}{(2)(0.00102)}=257.2 \mathrm{MPd}(37.3 \mathrm{ksi})
$$

Note that a general rule for a thin-walled pressure vessel is that the ratio of radius $R$ to wall thickness $t$ should be greater than 10 .

Stressed Volume of Spherical Shell

$$
V=\frac{4}{3}\left[(R+t)^{3}-R^{3}\right]
$$

where $V$ is the stressed volume. Using the previous values of $R$ and $t$ gives

$$
\begin{aligned}
V & =\frac{4}{3}\left[(12+0.040)^{3}-12^{3}\right] \\
& =\frac{4}{3}\left[(0.305+0.00102)^{3}-0.305^{3}\right] \\
& =381 \times 10^{-6} \mathrm{~m}^{3}\left(23.2 \mathrm{in.}^{3}\right)
\end{aligned}
$$

Probability of Failure (Test Specimen)

$$
F(x)=1-\exp \left[-\left(\frac{x-x_{u}}{x_{0}}\right)^{m}\right]
$$

where

$F(x)$ statistical fraction of specimens that failed at given stress or lower

$x \quad$ stress

$x_{u} \quad$ stress below which no specimens failed

$x_{0} \quad$ characteristic strength, stress at which 63.2 percent of specimens failed

m Weibull slope

Using $x=258.6 \mathrm{MPa}(37500 \mathrm{psi}), x_{u}=0$, $x_{0}=361.3 \mathrm{MPa}(52396 \mathrm{psi})$, and $\mathrm{m}=47.5$ gives

$$
F(x)=1-\exp \left[-\left(\frac{258.6-0}{361.3}\right)^{47.5}\right]=0.000000126
$$

Probability of Survival (Test Specimen)

$$
S_{1}=1-F(x)
$$

where $S_{1}$ is the probability of survival of the test specimen. For the value of $F(x)$ given above, $S_{1}$ is then 
$S_{1}=1-0.000000126=0.999999874$

Probability of Survival (Full-Size Structure)

$$
s_{2}=s_{1}^{\left(v_{2} / v_{1}\right)}
$$

where $S_{2}$ and $V_{2}$ are the probability of survival and stressed volume of the full-size structure, respectively, and $V_{1}$ is the stressed volume of the test specimen. For $V_{2}=0.000381 \mathrm{~m}^{3}\left(23.2 \mathrm{in.}^{3}\right)$, $v_{1}=0.805 \times 10^{-6} \mathrm{~m}^{3}(0.0491 \mathrm{in.3})$ and the value of 5 as given above gives

$$
S_{2}=0.999999874^{\left(0.000381 / 0.0805 \times 10^{-6}\right)}=0.999940
$$

ASME Code for Spherical Pressure Vessel Shell

$$
t=\frac{P R}{2 S E-0.2 P}
$$

where the parameters are as follows:

$$
\begin{array}{ll}
P & \text { internal pressure } \\
R & \text { inner radius } \\
S & \text { maximum allowable stress, } S=S_{u t} / n \\
S_{U t} & \text { ultimate tensile strength } \\
n & \text { safety factor } \\
E & \text { joint efficiency }
\end{array}
$$

For $P=1.72 \mathrm{MPa}(250 \mathrm{psi}), R=0.305 \mathrm{~m}$ (12 in.), $S_{u t}=310.3 \mathrm{MPa}(45 \mathrm{ksi}), n=4$, and $E=1$ the thickness becomes

$$
t=\frac{\left(1.72 \times 10^{6}\right)(0.305)}{\frac{2\left(310.3 \times 10^{6}\right)}{4}(1)-0.2\left(1.72 \times 10^{6}\right)}
$$

$$
=3.39 \mathrm{~mm}(0.133 \mathrm{in} .)
$$

APPENOIX B - DERIVATION OF A DESIGN EQUATION FOR SPHERICAL PRESSURE VESSEL SHELLS

Since the probability of survival $S$ is simply one minus the probability of failure. $S$ can be defined by

$$
S=1-F(x)=\exp \left[-\left(\frac{x-x_{u}}{x_{0}}\right)^{m}\right]
$$

The probability of survival of a full-size structure $\mathrm{S}_{2}$ in relation to the probability of survival of a coupon specimen $S_{1}$ is given by

$S_{2}=S_{1}^{v_{2} / V_{1}}=\left(1-F_{x}\right)^{v_{2} / V_{1}}=\left[\exp -\left(\frac{x-x_{u}}{x_{0}}\right)^{m}\right]^{v_{2} / V_{1}}$

where $V_{1}$ and $V_{2}$ are the volumes of the coupon specimen and the full-size structure, respectively. Simolifying gives

$$
s_{2}=\left[\exp -\left(\frac{x-x_{u}}{x_{0}}\right)^{m}\right]^{V_{2} / v_{1}}
$$

The volume of the walls of a spherical pressure vessel is given by

$$
V=\frac{4}{3}\left[(R+t)^{3}-R^{3}\right]
$$

where $V$ is the volume, $R$ is the inside radius, and $t$ is the wall thickness. Limiting our discussion to thin-walled spherical pressure vessels, the wall thickness can be defined by

$$
t=\frac{P R}{2 x}
$$

where $P$ is the internal pressure and $x$ is the tensile stress in the walls. Substituting Eq. (B5) into Eq. (B4) for $t$ and simplifying gives

$$
V=\frac{4}{3} R^{3}\left[\left(1+\frac{p}{2 x}\right)^{3}-1\right]
$$

which relates the full-size structure's stressed volume to the operating stress. Now substituting $\mathrm{Eq}$. (B6) into Eq. (B3) for $V_{2}$ gives

$$
S_{2}=\left[\exp -\left(\frac{x-x_{u}}{x_{0}}\right)^{m}\right]^{4 R^{3} / 3 V_{1}\left[(1+P / 2 x)^{3}-1\right]}
$$

Given the Weibull parameters for the material. internal pressure, and the required probability of survival and the inside radius of the vessel shell,

Eq. (B7) then contains only one unknown - the operating stress $x$. With the above design specifications, the operating stress can then be solved by iteration. Once the maximum operating stress has been established, the required thickness of the spherical pressure vesse? $\mathrm{Can}$ be determined from $\mathrm{Eq}$. (B5).

\section{REFERENCES}

Abelkis, P.R. and Hudson, C.M., eds., Design of Fatigue and Fracture Resistant Structures, ASTM STP-76I, ASTM, Philadelphia, PA, 1980.

ASME Boiler and Pressure Vessel Code. American Society of Mechanical Engineers, NY, 1987.

ASTM B 557-84, Metals Test Method and Analytical Procedures, Annual Book of ASTM Standards, Vol. 03.01, ASTM, Philadelphia, PA, 1986.

Augusti, G., Baratta, A., and Casciati, F., Probabilistic Methods in Structural Analysis. Chapman and Hall, London, 1984.

Barnett, R.L., Costello, J.F., and Herman, P.C., "The Odds Against Fracture," Machine Design, Vol. 38, No. 26, pp. 184-192, 1966.

Department of Defense, Metallic Materials and Elements for Aerospace Vehicle Structures, MIL-HOBK-5E, June 1, 1987.

DeSalvo, G.J.. Theory and Structural Design Applications of Weibull Statistics, WANL-TME-2688,

Westinghouse Astronuclear Laboratory. Pittsburgh, PA., 1970.

Gere, J.M. and Timoshenko, S., Mechanics of Materials, Wadsworth. Inc., Belmont, California, 1984.

Heller, R.A., ed., Probabilistic Aspects of Fatigue, ASTM STP-511, ASTM, Philadelphid, PA, 1972. 


\section{ORIGINAL PAGE IS \\ OF POOR QUALITY}

Ioannides, E. and Harris, T.A., "A New Fatigue Life Model for Rolling Bearings," Trans. ASME, J.

Tribology, Vol. 107, No. 3, July 1985, pp. 367-378.

Johnson, L.G., The Statistical Treatment of Fatigue Experiments. Rept. No. GMR-202, General Motors

Corp., Apr. 1959.

Little, R.E. and Ekvall, C., eds., Statistical Analysis of Fatigue Data, ASTM STP-744. ASTM, Philadelphia, PA, 1979.

Moyer, C.A., Bush, J.J., and Ruley, B.T., The Weibull Distribution for Fatigue Life, Proposed addition to ASTM STP 91-A, ASTM. Philadelphia, PA, 1962.
Shih, I.I., An Evaluation of the Probabilistic Approach to Brittle Design. Scientific Paper 78-903-CTRDP-P2, Westinghouse Electric Corp., 1980.

Weibull. W. "The Phenomenon of Rupture in Solids," Ingeniörs Vetenskaps Akademien, No. 153, 1939.

Weibull, W., "A Statistical Distribution of Wide Applicability," Journal of Applied Mechanics,

Vol. 18, No. 3, Sept. 1951, pp. 293-297.

Zaretsky, E.V., "Fatigue Criterion to System Design, Life, and Reliability," Trans. AIAA, J. Propulsion and Power, Vol. 3, No. I, Jan.-Feb. 1987, pp. 76-83.

TABLE I. - RESULTS OF TWO-PARAMETER WEIBULL ANALYSES OF FRACTURE DATA

FROM TWO BATCHES OF A357-T6 CAST ALUMINUM SPECIMENS

\begin{tabular}{|c|c|c|c|c|c|c|c|c|}
\hline \multirow[t]{3}{*}{ Batch } & \multirow{3}{*}{$\begin{array}{l}\text { Sample } \\
\text { size }\end{array}$} & \multirow{3}{*}{$\begin{array}{l}\text { Wetbull } \\
\text { modulus, } \\
m\end{array}$} & \multicolumn{6}{|c|}{ Fracture strength } \\
\hline & & & \multicolumn{2}{|c|}{ Characteristic, $x_{0}$} & \multicolumn{2}{|c|}{ Mean } & \multicolumn{2}{|c|}{$\begin{array}{c}0.0001-\text { Percent } \\
\text { levela }\end{array}$} \\
\hline & & & $M P_{d}$ & psi & $\mathrm{MPa}$ & psi & $\mathrm{MPa}$ & psi \\
\hline $\begin{array}{l}1 \\
2\end{array}$ & $\begin{array}{l}354 \\
388\end{array}$ & $\begin{array}{l}47.5 \\
30.6\end{array}$ & $\begin{array}{l}361.3 \\
357.6\end{array}$ & $\begin{array}{ll}52 & 396 \\
53 & 311\end{array}$ & $\begin{array}{l}357.0 \\
361.0\end{array}$ & $\begin{array}{ll}51 & 783 \\
52 & 362\end{array}$ & $\begin{array}{l}270.1 \\
234.1\end{array}$ & $\begin{array}{ll}39 & 178 \\
33 & 948\end{array}$ \\
\hline \multicolumn{3}{|c|}{ rence, pe } & \multicolumn{2}{|c|}{1.7} & \multicolumn{2}{|c|}{1.1} & \multicolumn{2}{|c|}{14.3} \\
\hline
\end{tabular}

afracture strength at a 99.9999 percent probability of survival.

TABLE II. - EFFECT OF VARYING SAMPLE SIZE ON WEIBULL PARAMETERS AND ESTIMATED

FRACTURE SIRENGTHS OF A357-T6 CAST ALUMINUM SPECIMENS

\begin{tabular}{|c|c|c|c|c|c|c|c|c|c|c|c|}
\hline \multirow[t]{3}{*}{ Batch } & \multirow{3}{*}{$\begin{array}{l}\text { Sample } \\
\text { size }\end{array}$} & \multirow{3}{*}{$\begin{array}{l}\text { Weibull } \\
\text { modulus, } \\
\mathrm{m}\end{array}$} & \multicolumn{9}{|c|}{ Fracture strength } \\
\hline & & & \multicolumn{3}{|c|}{ Characteristic, $x_{0}$} & \multicolumn{3}{|c|}{ Mean } & \multicolumn{3}{|c|}{$0.0001-P e r c e n t$ level } \\
\hline & & & $\mathrm{MPa}$ & $p s i$ & $\begin{array}{l}\text { Difference, } \\
\text { percent }\end{array}$ & $\mathrm{MPa}$ & psi & $\begin{array}{c}\text { Difference, } \\
\text { percent }\end{array}$ & $\mathrm{MPa}$ & psi & $\begin{array}{c}\text { Difference, } \\
\text { percent }\end{array}$ \\
\hline 1 & $\begin{array}{r}354 \\
30 \\
20 \\
10\end{array}$ & $\begin{array}{l}47.5 \\
47.5 \\
35.7 \\
59.0\end{array}$ & $\begin{array}{l}361.3 \\
358.9 \\
361.5 \\
357.6\end{array}$ & $\begin{array}{ll}52 & 396 \\
52 & 054 \\
52 & 433 \\
51 & 869\end{array}$ & $\begin{array}{l}-- \\
0.6 \\
.1 \\
1.0\end{array}$ & $\begin{array}{l}357.0 \\
354.7 \\
356.0 \\
354.2\end{array}$ & $\begin{array}{ll}51 & 783 \\
51 & 444 \\
51 & 626 \\
51 & 377\end{array}$ & $\begin{array}{l}-. . \\
0.6 \\
.3 \\
.8\end{array}$ & $\begin{array}{l}270.1 \\
268.3 \\
245.4 \\
282.9\end{array}$ & $\begin{array}{ll}39 & 178 \\
38 & 912 \\
35 & 594 \\
41 & 034\end{array}$ & $\begin{array}{r}0.7 \\
9.1 \\
4.7\end{array}$ \\
\hline 2 & $\begin{array}{r}388 \\
30 \\
20 \\
10\end{array}$ & $\begin{array}{l}30.6 \\
46.9 \\
41.9 \\
94.5\end{array}$ & $\begin{array}{l}367.6 \\
362.6 \\
367.7 \\
367.0\end{array}$ & $\begin{array}{ll}53 & 311 \\
52 & 584 \\
53 & 321 \\
53 & 229\end{array}$ & $\begin{array}{l}-1 . \\
1.4 \\
0 \\
.2\end{array}$ & $\begin{array}{l}361.0 \\
358.3 \\
362.8 \\
364.8\end{array}$ & $\begin{array}{ll}52 & 362 \\
51 & 961 \\
52 & 618 \\
52 & 910\end{array}$ & $\begin{array}{r}-.- \\
0.8 \\
.5 \\
1.0\end{array}$ & $\begin{array}{l}234.1 \\
270.1 \\
264.4 \\
317.1\end{array}$ & $\begin{array}{ll}33 & 948 \\
39 & 169 \\
38 & 352 \\
45 & 990\end{array}$ & $\begin{array}{l}---- \\
15.4 \\
13.0 \\
35.5\end{array}$ \\
\hline
\end{tabular}

TABLE III. - SPHERICAL PRESSURE VESSEL SHELL PARAMETERS RESULTING FROM ASME AND WEIBULL DESIGN METHODS

[Inside radius of shell, $0.305 \mathrm{~m}$ (12 in.); internal pressure, $1.72 \mathrm{MPa}(250 \mathrm{psi}) . \mathrm{J}$

\begin{tabular}{|c|c|c|c|c|c|}
\hline \multirow{2}{*}{$\begin{array}{l}\text { Design } \\
\text { procedure }\end{array}$} & \multicolumn{2}{|c|}{ Shell thickness } & \multicolumn{2}{|c|}{ Weight } & \multirow{2}{*}{$\begin{array}{l}\text { Probability } \\
\text { of survival, a } \\
\text { percent }\end{array}$} \\
\hline & $\mathrm{mm}$ & in. & $\mathrm{kg}$ & $\mathrm{Ib}$ & \\
\hline $\begin{array}{l}\text { ASME } \\
\text { Weibull }\end{array}$ & $\begin{array}{r}3.39 \\
.141\end{array}$ & $\begin{array}{r}0.133 \\
.055\end{array}$ & $\begin{array}{r}10.8 \\
4.4\end{array}$ & $\begin{array}{r}23.8 \\
9.8\end{array}$ & $\begin{array}{r}100.000000 \\
99.999998\end{array}$ \\
\hline
\end{tabular}

according to Weibull statistics. 

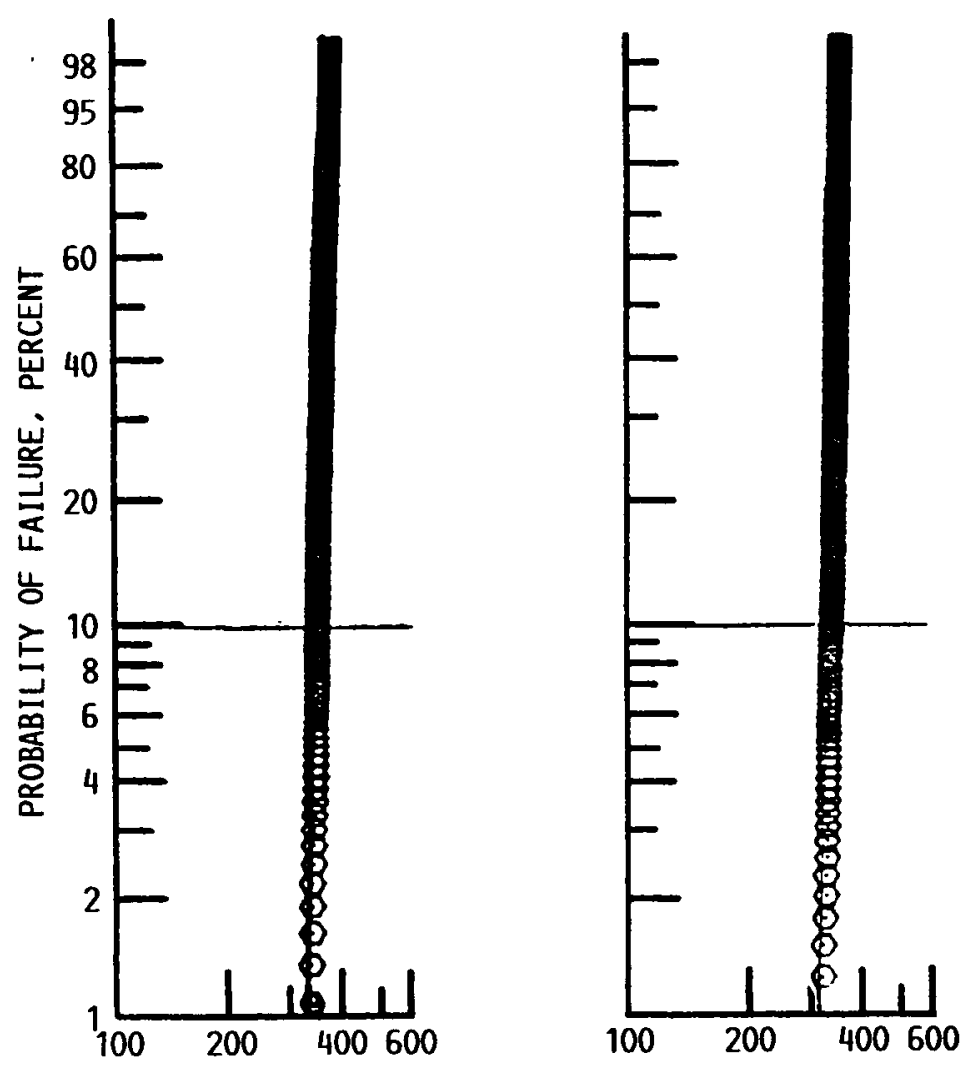

FRACTURE STRENGTH, MPa

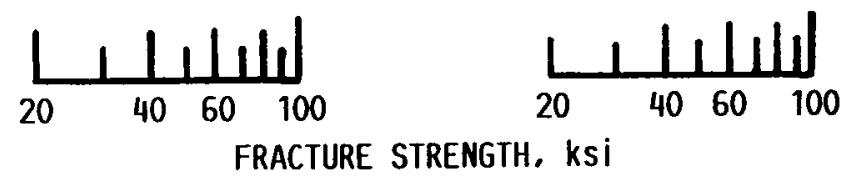
(a) BATCH 1, 354
(b) BATCH 2.388
SPECIMENS TESTED
SPECIMENS TESTED

FIG. 1 TWO-PARAMETER WEIBULL PLOTS OF FRACTURE STRENGTH OF A357-T6 CAST ALUMINUM 




FIG. 2 ESTIMATED FAILURE DISTRIBUTIONS OF BATCHES 1 AND 2: MATERIAL, A357-T6 CAST ALUMINUM 

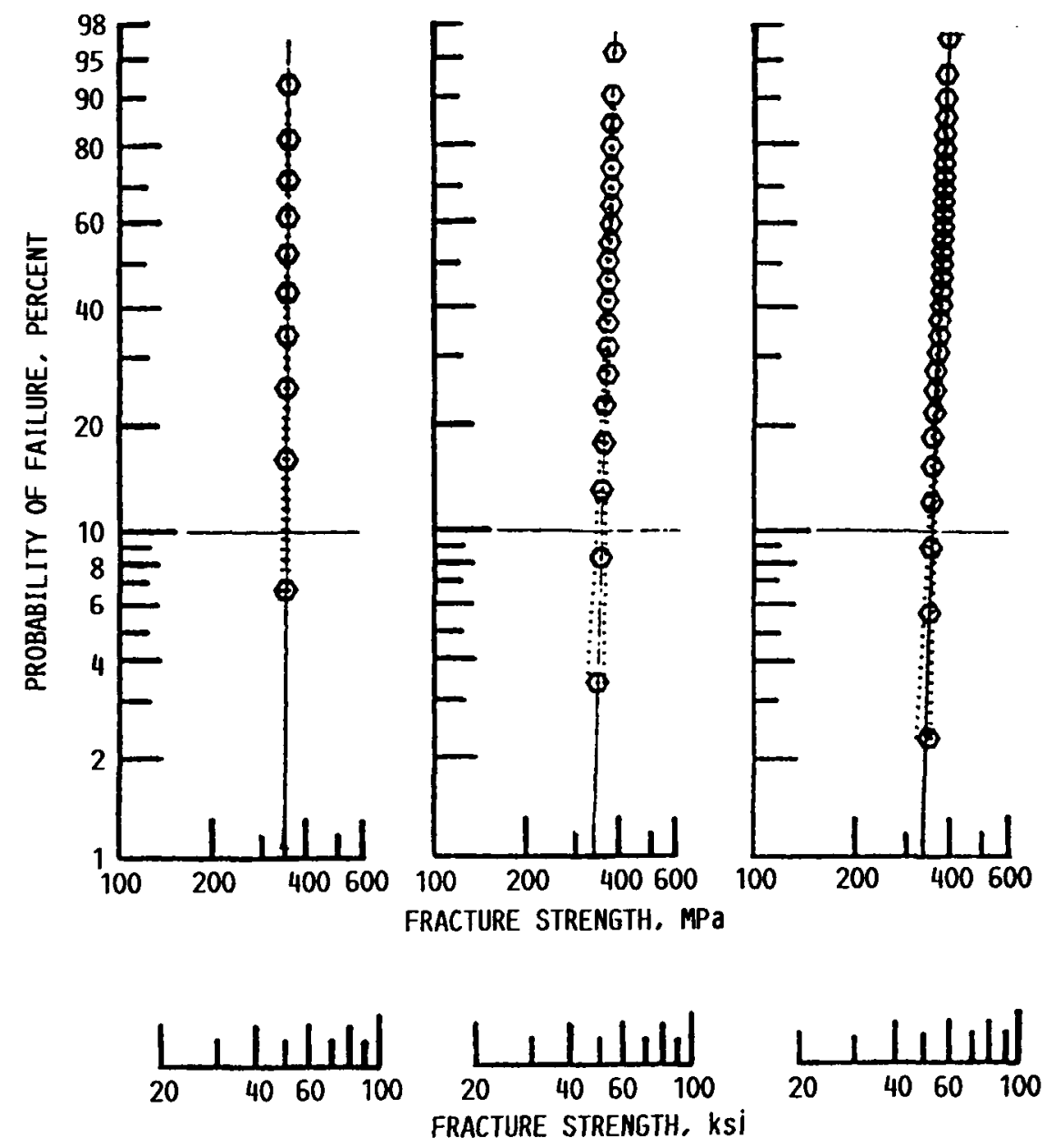
(a) 10 SPECIMENS
(b) 20 SPECIMENS
(c) 30 SPECIMENS

FIG. 3 TWO-PARAMETER WEIBULL PLOTS OF RANDOMLY SELECTED DATA FROM BATCH 2 WITH 95-PERCENT CONFIDENCE LIMITS 




(b) BATCH 2

FIG. 4 EFFECT OF VARYING SAMPLE SIZE ON ESTIMATE OF FRACTURE STRENGTH OF A357-T6 CAST ALUMINUM 




FIG. 5 EFFECT OF SAMPLE SIZE ON 95-PERCENT CONFIDENCE LIMITS OF A357-T6 CAST ALUMINUM: SAMPLE SIZES, 7. 8. 11, 17, 35, AND 88.

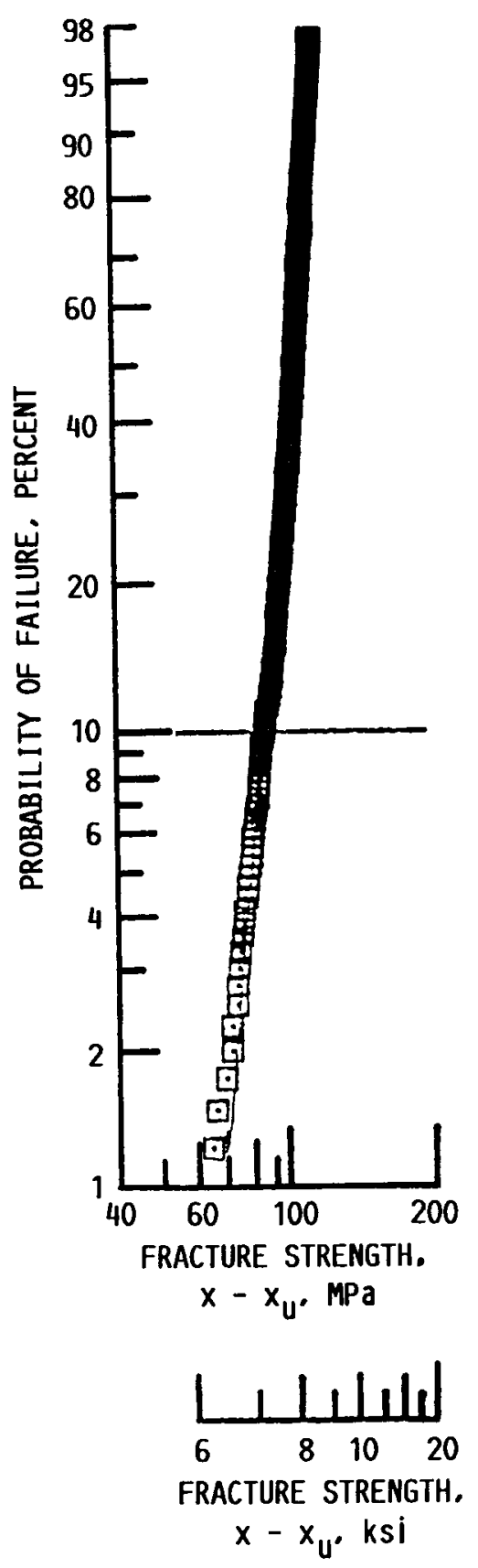

FIG. 6 THREE-PARAMETER WEIBULL PLOT OF BATCH 2 MATERIAL. A357-T6 CAST ALUMINUM: $x_{u}=262 \mathrm{MPa}$ (38 ksi): 388 SPECIMENS TESTED. 


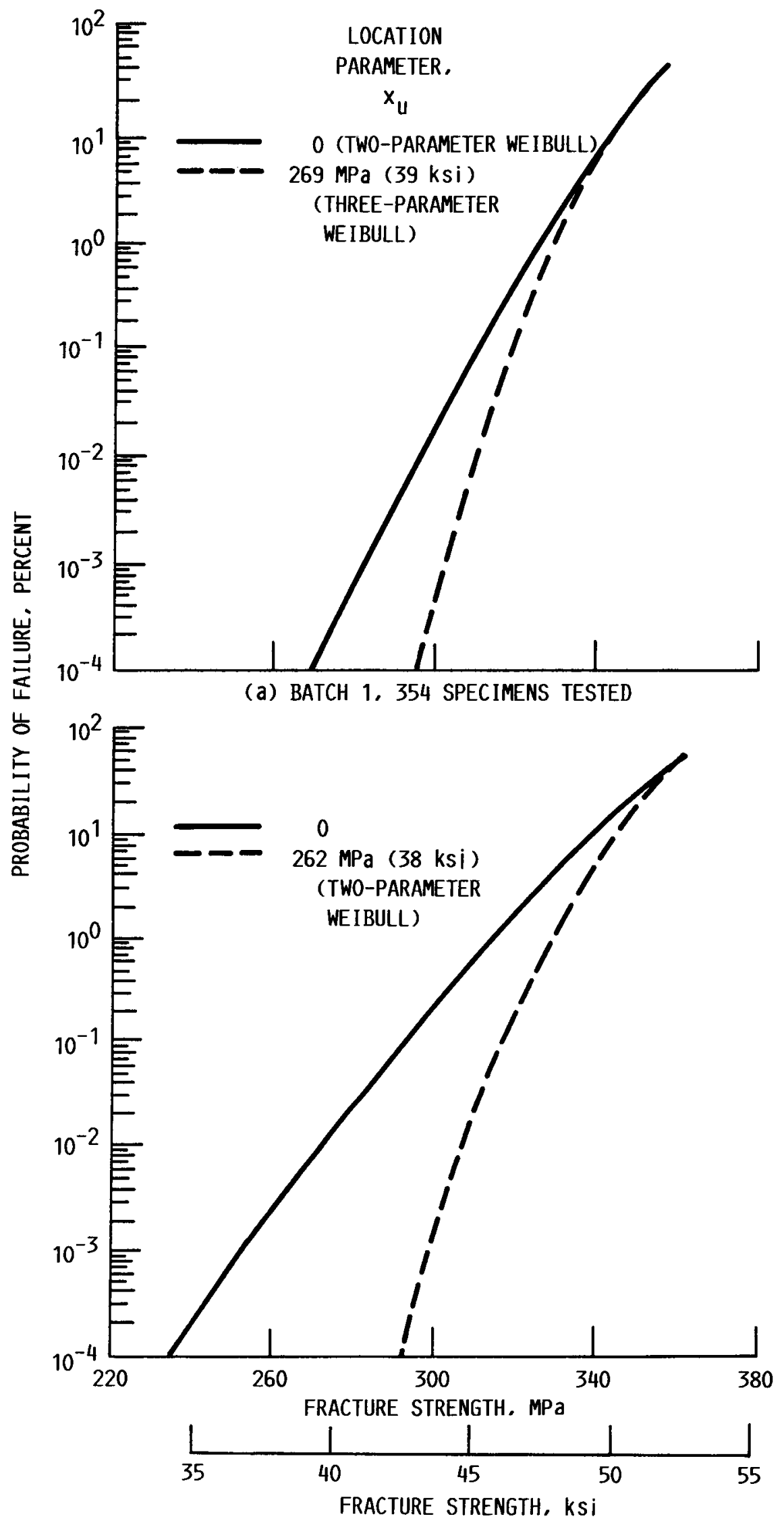

(b) BATCH 2, 388 SPECIMENS TESTED

FIG. 7 TWO- AND THREE-PARAMETER WEIBULL ANALYSES OF A357-T6 CAST ALUMINUM 


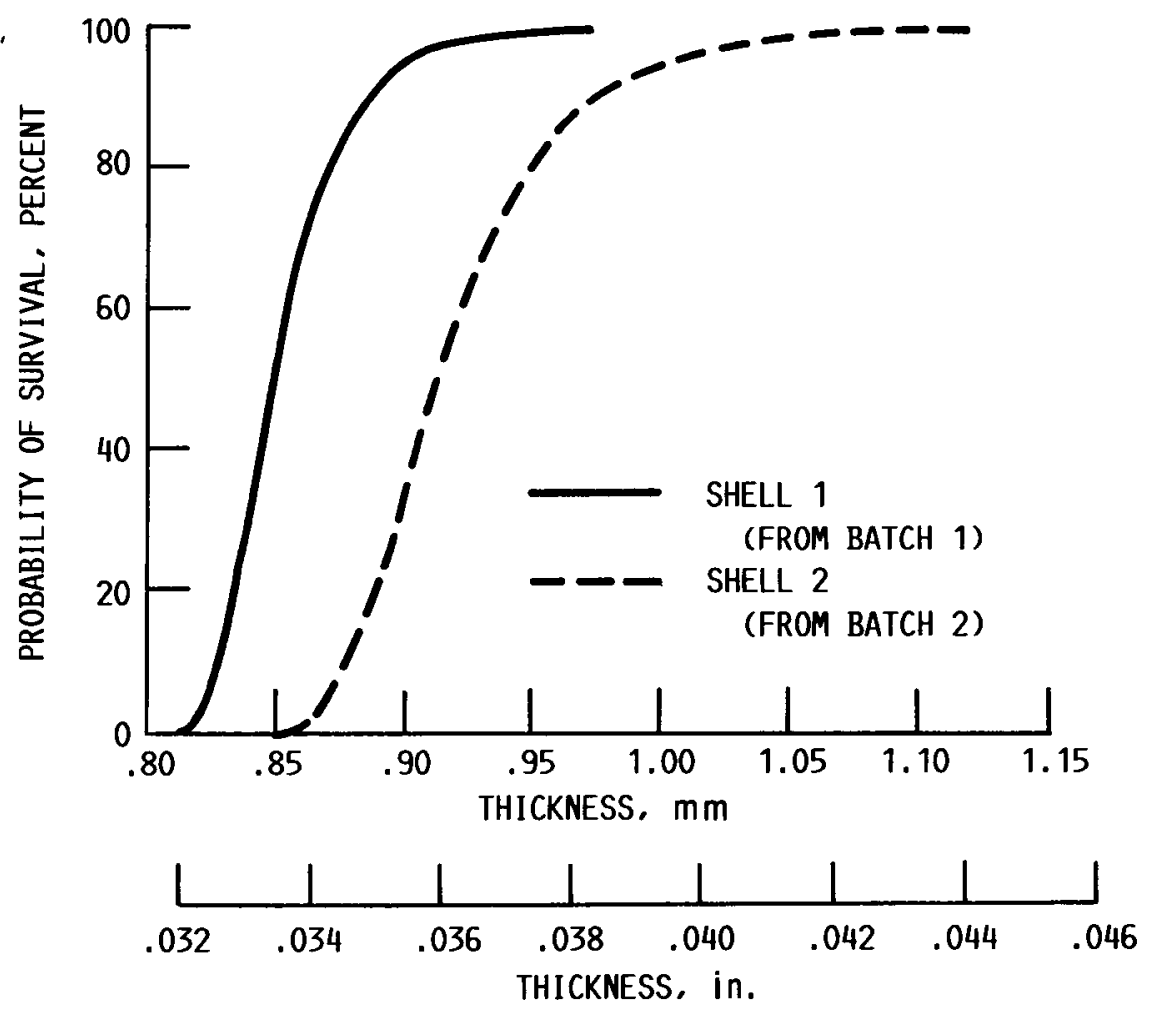

FIG. 8 EFFECT OF SHELL THICKNESS ON PROBABILITY OF SURVIVAL OF A357-T6 CAST ALUMINUM: SHELL INSIDE DIAMETER, $0.305 \mathrm{~m}$ ( $12 \mathrm{in.}$ ): INTERNAL PRESSURE, $1.72 \mathrm{MPa}$ (250 psi ) 


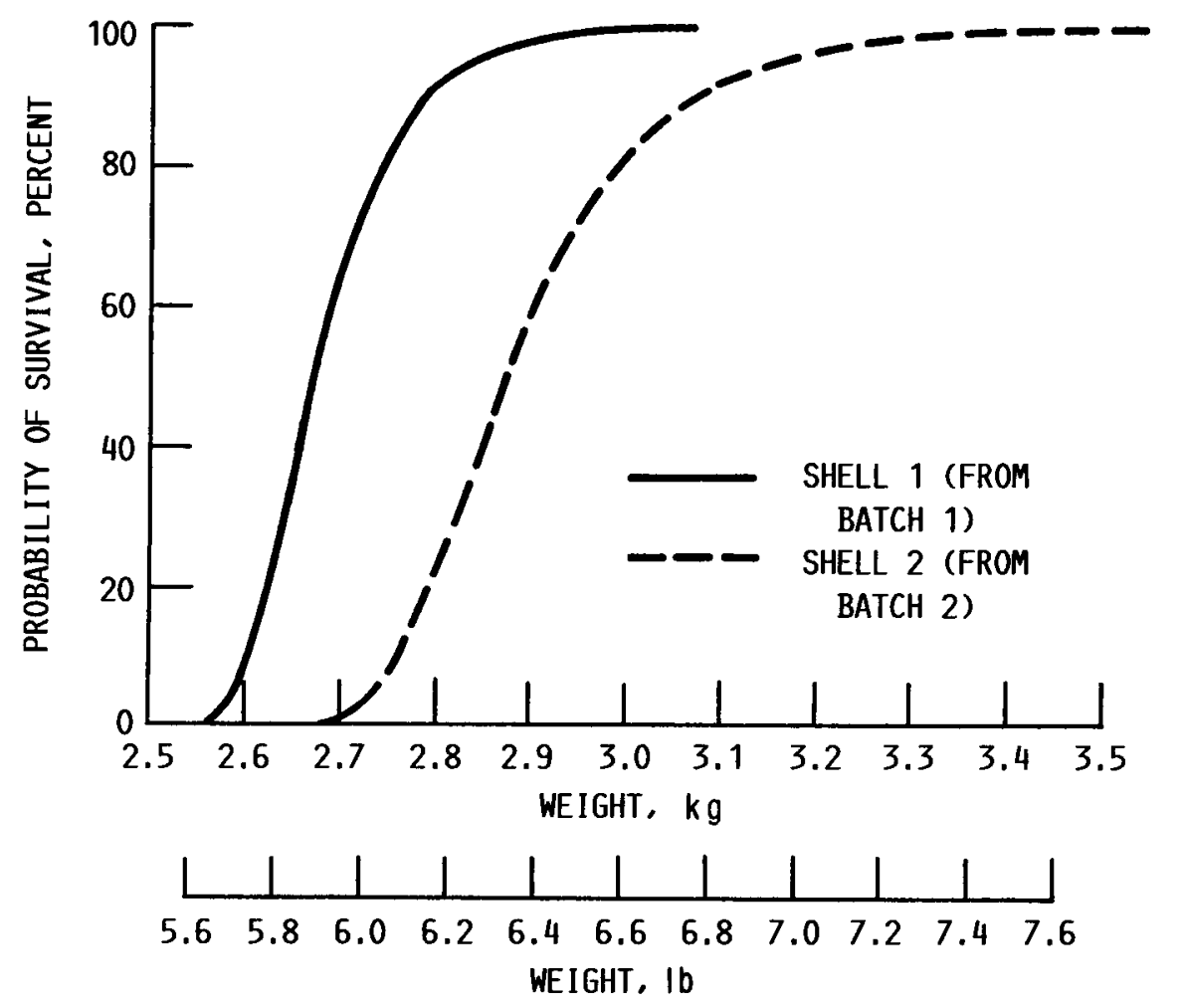

FIG. 9 EFFECT OF SHELL WEIGHT ON PROBABILITY OF SURVIVAL OF A357-T6 CAST ALUMINUM: SHELL INSIDE DIAMETER, $0.305 \mathrm{~m}$ (12 in.): INTERNAL PRESSURE: $1.72 \mathrm{MPa}$ (250 psi): MATERIAL DENSITY, $2.68 \mathrm{~g} / \mathrm{cm}^{3}(0.097 \mathrm{lb} / \mathrm{in.} 3)$ 


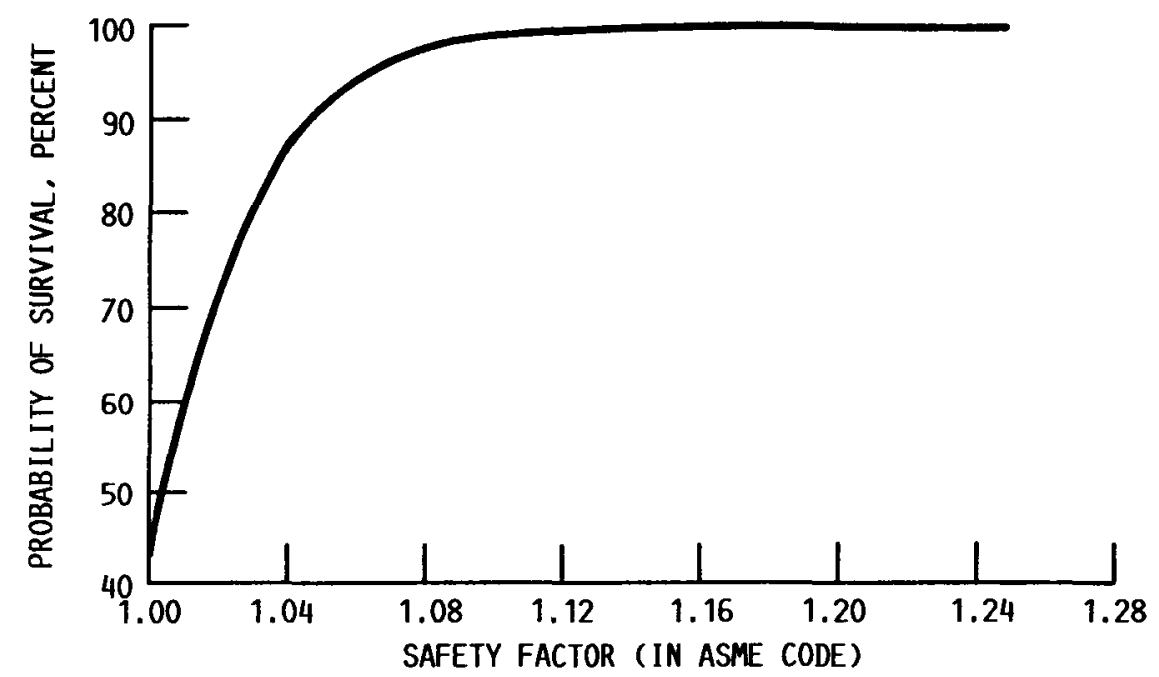

FIG. 10 CORRELATION BETWEEN PROBABILITY OF SURVIVAL AND SAFETY FACTOR FOR SPHERICAL PRESSURE VESSEL SHELL: FRACTURE STRENGTH OF A357-T6 CAST ALUMINUM. $310 \mathrm{MPa}$ (45 ksi) (HANDBOOK VALUE) 


\begin{tabular}{|c|c|c|c|c|}
\hline $\begin{array}{l}\text { 1. Report No. } \\
\text { NASA TM-102000 }\end{array}$ & \multicolumn{2}{|c|}{ 2. Government Accession No. } & \multicolumn{2}{|c|}{ 3. Recipient's Catalog No. } \\
\hline \multirow{2}{*}{\multicolumn{5}{|c|}{ Investigation of Weibull Statistics in Fracture Analysis of Cast Aluminum }} \\
\hline & & & & \\
\hline \multirow[t]{2}{*}{$\begin{array}{l}\text { 7. Author(s) } \\
\text { Frederic A. Holland, Jr., }\end{array}$} & Zaretsky & & \multicolumn{2}{|c|}{$\begin{array}{l}\text { 8. Performing Organization Report No. } \\
\text { E-4452 }\end{array}$} \\
\hline & & & \multicolumn{2}{|l|}{$\begin{array}{l}\text { 10. Work Unit No. } \\
505-63-1 D\end{array}$} \\
\hline \multirow{2}{*}{\multicolumn{3}{|c|}{$\begin{array}{l}\text { 9. Performing Organization Name and Address } \\
\text { National Aeronautics and Space Administration } \\
\text { Lewis Research Center } \\
\text { Cleveland, Ohio } 44135-3191\end{array}$}} & \multicolumn{2}{|c|}{ 11. Contract or Grant No. } \\
\hline & & & \multirow{2}{*}{\multicolumn{2}{|c|}{$\begin{array}{l}\text { 13. Type of Report and Period Covered } \\
\text { Technical Memorandum }\end{array}$}} \\
\hline \multirow{2}{*}{\multicolumn{3}{|c|}{$\begin{array}{l}\text { 12. Sponsoring Agency Name and Address } \\
\text { National Aeronautics and Space Administration } \\
\text { Washington, D.C. 20546-0001 }\end{array}$}} & & \\
\hline & & & \multicolumn{2}{|c|}{ 14. Sponsoring Agency Code } \\
\hline \multicolumn{5}{|c|}{$\begin{array}{l}\text { 15. Supplementary Notes } \\
\text { Prepared for the Failure Prevention and Reliability Conference sponsored by the American Association of } \\
\text { Mechanical Engineers, Montreal, Canada, September } 17-20,1989 \text {. }\end{array}$} \\
\hline \multicolumn{5}{|c|}{$\begin{array}{l}\text { 16. Abstract } \\
\text { The fracture strengths of two large batches of A357-T6 cast aluminum coupon specimens were compared by } \\
\text { using two-parameter Weibull analysis. The minimum number of these specimens necessary to find the fracture } \\
\text { strength of the material was determined. The applicability of three-parameter Weibull analysis was also investi- } \\
\text { gated. A design methodology based on the combination of elementary stress analysis and Weibull statistical analysis } \\
\text { is advanced and applied to the design of a spherical pressure vessel shell. The results from this design method- } \\
\text { ology are compared with results from the applicable ASME pressure vessel code. }\end{array}$} \\
\hline \multicolumn{2}{|c|}{$\begin{array}{l}\text { 17. Key Words (Suggested by Author(s)) } \\
\text { Weibull statistics; Probability of failure; Fracture strength; } \\
\text { Sample size; Failure distribution; Pressure vessel shell }\end{array}$} & \multicolumn{3}{|c|}{$\begin{array}{l}\text { 18. Distribution Statement } \\
\text { Unclassified-Unlimited } \\
\text { Subject Category } 37\end{array}$} \\
\hline $\begin{array}{l}\text { 19. Security Classif. (of this report) } \\
\text { Unclassified }\end{array}$ & $\begin{array}{l}\text { 20. Security Classif. ( } \\
\text { Uncl }\end{array}$ & $\begin{array}{l}f \text { this page) } \\
\text { assified }\end{array}$ & $\begin{array}{c}\text { 21. No of pages } \\
18\end{array}$ & $\begin{array}{l}\text { 22. Price* } \\
\text { A03 }\end{array}$ \\
\hline
\end{tabular}

